\title{
Optimum Autofrettage Pressure of Hydrogen Valve Using Finite Element and Fatigue Analysis
}

\author{
Slawomir Kedziora* ${ }^{\circledR}$, Thanh Binh Cao \\ University of Luxembourg, Campus Kirchberg, Luxembourg, Luxembourg \\ Email: ^slawomir.kedziora@uni.lu
}

How to cite this paper: Kedziora, S. and Cao, T.B. (2020) Optimum Autofrettage Pressure of Hydrogen Valve Using Finite Element and Fatigue Analysis. Engineering, $12,1-24$.

https://doi.org/10.4236/eng.2020.121001

Received: November 5, 2019

Accepted: January 10, 2020

Published: January 13, 2020

Copyright $\odot 2020$ by author(s) and Scientific Research Publishing Inc. This work is licensed under the Creative Commons Attribution International License (CC BY 4.0).

http://creativecommons.org/licenses/by/4.0/

\section{(c) (i) Open Access}

\begin{abstract}
The presented article shows an estimation method of optimum autofrettage pressure taking into consideration subsequent cyclic loading. An autofrettage process is used in pressure vessel applications for strength improvement. The process relies on applying massive pressure that causes internal portions of the part to yield plastically, resulting in internal compressive residual stresses when pressure is released. Later applied working pressure (much lower than autofrettage pressure) creates stress reduced by the residual compressive stress improving the structural performance of the pressure vessels. The optimum autofrettage pressure is a load that maximizes the fatigue life of the structure at the working load. The estimation method of that pressure of a hydrogen valve is the subject of the presented work. Finite element and fatigue analyses were employed to investigate the presented problem. An automated model was developed to analyze the design for various autofrettage pressures. As the results of the procedure, the optimum autofrettage pressure is determined. The research has shown that the developed method can profitably investigate the complex parts giving the autofrettage load that maximizes the fatigue life. The findings suggest that the technique can be applied to a large group of products subjected to the autofrettage process.
\end{abstract}

\section{Keywords}

Autofrettage, Hydrogen Valve, Finite Element Analysis, Fatigue, Design

\section{Introduction}

An autofrettage process is widely used in pressure-vessel applications for fatigue resistance improvement of parts like pipes, barrels, tanks, pressure lines, and 
valves. An idea of autofrettage pressure is not new; Jacob from the French artillery suggested in 1907 [1] to use the autofrettage process for increasing the allowable pressure in gun barrels so to extend their firing range. A mathematical foundation for understanding the physics of the autofrettage process was given in the 18th century by a French mathematician Gabriel Lame in work [2]. The autofrettage process depends on applying massive pressure that causes internal portions of the part to yield plastically, resulting in internal compressive residual stresses when pressure is released. Then when working pressure is applied (much lower than autofrettage pressure), the residual compressive stress helps to resist a newly created stress. The detailed explanation of improvement of the fatigue file can be done relying on an influence of mean stress on the lifetime of parts subjected to cycling loads. The compression mean stress significantly extends the lifetime of those parts. A similar process in its effect is a swage process [3] or shot-peening one [4]; both of them generate residual compressive stress, which significantly helps improve the fatigue life of the parts.

A method of an estimation of an autofrettage pressure is developed in the presented work. The approach is focusing on maximization of the fatigue life of parts with complex geometry. In detail, the fatigue life is used as a criterion for the optimum autofrettage pressure. As will be shown, a limitation is only material fatigue data. This constraint is weakened by a proposition of material data estimation based on tensile test results taken from the relevant literature. Finally, a complete procedure of the autofrettage pressure evaluation is developed.

An application of the method is shown based on two examples, the first one a standard problem of a thick-walled tube and the second one a complex hydrogen valve. The first example is taken from the work of [5], in which authors proposed an analytical method of the estimation of the autofrettage pressure. A comparison of results between both methods is presented in the section-Results and Discussion. The second example of an implementation of the proposed method in the development of the hydrogen valve and the complete process is shown how to maximize the fatigue life by a selection of the autofrettage pressure.

The authors know that the proposed method should not be used without testing because of the stochastic nature of fatigue and real parts defects; validation testing must always be done. Nevertheless, the method can give a range of beneficial autofrettage pressure, helping to specify the autofrettage load considering test results and other constraints. The authors believe that the proposed steps can considerably reduce the time of development of pressure-vessels and improve their structural performance for cyclic loading.

\section{Review of Literature}

An idea of a method of an estimation optimum of the autofrettage pressure is not a new one; for example, authors [5] proposed the method to determine that pressure based on the analytical equation for the thick-walled tube. This article belongs to a group of articles ([5] [6] [7]). The authors determine any autofret- 
tage pressure based on the assumption that a maximum von Mises stress or Tresca stress at a critical section has a minimum value at an operating pressure for the specific autofrettage pressure. Assuming that the critical section is an elasto-plastic juncture (radius) of the thick-walled tube. The elasto-plastic radius was determined by equating radial stress components at the elastic-plastic interface. The elasto-plastic radius is dependent on autofrettage pressure. The authors [5] searched for the minimum of the maximum von Mises stress at the elasto-plastic interface at the operating pressure as results getting the optimum autofrettage pressure. The study has attempted to explain the relationship between the autofrettage pressure and the maximum equivalent stress at the elasto-plastic radius.

The author used the bilinear kinematic model of the plasticity of the tube material and used Lamés equations to solve the problem. The boundary conditions were used, which reflects plain strain simulating a long infinity tube loaded by internal pressure. The model allows taking into account the Bauschinger effect [8]. The same tube was taken as an example of the test case for the presented work.

The described method has an assumption that causes questionable results. The assumption that the von Mises stress is at the critical section (elasto-plastic radius) is a suitable parameter for fatigue strength assessment of the thick-tubes. As shown in the presented work, the optimum autofrettage pressure at the predicted value [5] does not exist if the fatigue life is taken as the assessment criterion. That effect can be seen when detail FEA results are analyzed, and instead of the von Mises stress, the fatigue life is taken into consideration as the structural assessment parameter. Nevertheless, the work is valuable because it gives motivation for further development in this area and provides a solid foundation for the presented work.

Most of the time, authors were focused on simple thick-walled pipes as a modeling example; this is an obvious consequence of using an analytical method based on the Lame's equations. Some works used the finite element method to solve the problem for parts with complex geometry; for example, the work [9]. The authors, as an example, use the part with complex shape, and they used FEA to find stress and strain distributions and then develop a simplified method to make fatigue prediction based on fracture mechanics. The proposed method was successfully applied to real diesel injection components, according to the authors. This is an interesting work since the presented project is focused on the estimation of fatigue life, including the influence of the autofrettage process.

A recent study [10] has been conducted using the nonlinear finite element method for the automotive hydrogen valve, and the author used iterative method for estimation of the autofrettage pressure for an aluminum valve body. The routine has been based on the assumption that an effective stress intensity in a critical stress concentration location is not higher than the stress intensity threshold ( $\mathrm{R}<0$ and mode $\mathrm{I}-$ opening). Additionally, the zone of the compres- 
sion stress should be significantly higher in comparison with the roughness of the part surface. Under these conditions, cracks cannot grow, and the problem can be just reduced to an elastic-plastic finite element analysis of the crack-free valve with the autofrettage step and then one-load cycle steps. The proposed method requires an iterative approach with a criterion that the maximum autofrettage pressure should produce an equivalent strain level at the critical notch that is below the fracture strain of the valve material. The suggested method is complicated, and there are stages/steps, which can introduce an error. For example, the decision whether the size of the compression stress zone is significantly greater than roughness in the critical location; that can be done only based on subjective judgment. The advantage of the procedure is one; it can be applied for every aluminum complex geometry parts. It can be imagined that implementing other materials than aluminum is workable; a few minor adjustments to the strain limit criterion based on properties of new materials are needed.

An inspiring fatigue prediction method of parts subjected to an autofrettage process described the work [11]. The authors focused there on the high cycle fatigue of double notched tensile specimens ( 3555 steel) subjected to autofrettage to create residual compresses stress in the notch areas. The authors observed that higher initial compressive residual stress magnitude did not automatically lead to longer fatigue life. Finite element analysis using a cyclic plasticity material model (Chaboche nonlinear kinematic hardening model with the best fit to the experimental data) shows that behavior. In detail, it was caused due to combined residual stress redistribution under fatigue test cyclic loading and cyclic hardening effects. The fatigue life methodology based on the stress life approach and improved by a critical distance method. The applied stress life procedure is based on the von Mises stress (equivalent stress), assuming proportionality of effective mean stress and hydrostatic pressure. The fatigue life was evaluated by comparing the calculated maximum equivalent stress amplitude at the notch root with the experimental uniaxial SN curves and Haigh diagram.

It was shown that the method gave good agreement with experimental results with no induced residual stress only. The results for specimens with induced residual stress are more conservative than the prediction; nonetheless, the degree of conservatism is lower than that one in the conventional stress life approach. Therefore, the method was assumed as satisfactory by the authors.

The research to date has not been able to show a method of the estimation of autofrettage pressure for the complex parts convincingly. Most of the time, the articles concern simple thick-wall tubes, and if complex geometry is present, they are limited to one particular configuration and material or burden with subjective assessment.

To conclude this section, the literature identifies a gap for the autofrettage pressure estimation for the complex geometry parts and different metals. The authors of the presented work developed a new method to fulfill the existing gap on the ground of available knowledge and technology nowadays. 


\section{Methods}

The main idea of the estimation method of the autofrettage pressure was to develop a straightforward and intuitive procedure using available technology. Consequently, non-linear finite element analysis and advanced fatigue analysis, which together can deliver maximum benefits, have been chosen as the main methods. In detail, the FE and advanced fatigue analyses can be combined, producing as results the fatigue life of the parts subject to autofrettage pressure and subsequently pressure cycle loading. Moreover, the optimum autofrettage pressure can be determined that maximizes the fatigue life of applied cyclic loading. This straightforward approach can be then applied for any geometry and metal material.

An issue with an accuracy of strain/stress estimation caused by the mesh density of a complicated geometry part can be solved by implementing the submodeling of critical regions.

The next potential problem can occur because the method requires detailed material fatigue data, which are not available immediately. Therefore, the fatigue data can be estimated based on tensile test results on the ground of work of [12] and [13]. Taking those elements into account, the method is ready to apply for any geometry and different metal material.

The software platform for the method was selected from commercial packages existing on the market and having excellent user feedback, namely, for FEA-ANSYS 19 [14] and for fatigue analyses nCode [15]. A combined analysis model was built using both software in ANSYS Workbench, makes feasible to integrate all processes into one environment-there is no need for manual data extraction and a transfer between different software. The built FE model, and the fatigue one are fully automated, producing the fatigue life for the requested autofrettage pressure for defined user parameters.

In the following part of the current section, the FE models and the developed procedure are presented in detail. In subsections, the elaborated method is broken down into fundamental parts to help a reader to understand the procedure. The explanation is done based on two different examples in terms of design and material. The examples were borrowed from the related literature.

\subsection{Thick-Walled Tube Finite Element Model}

As it was mentioned, two FE models were built to analyze and test the proposed method, first one-the thick-walled tube design, which comes from the work [5] (Figure 1). The case-study approach was chosen to make a result comparison, to have a reference point, to gain a detailed understanding of physics. The material model was slightly modified, in comparison with the early study to improve prediction of plastic strain distributions; instead of a bilinear model, a multilinear model with kinematic hardening was used (Figure 2). Fatigue properties of steel alloy AISI 4340 needed for the proposed method were selected from the study [16] since that material is well tested, and data are available in the relevant literature. The summary of the used material data is presented in Table 1. 


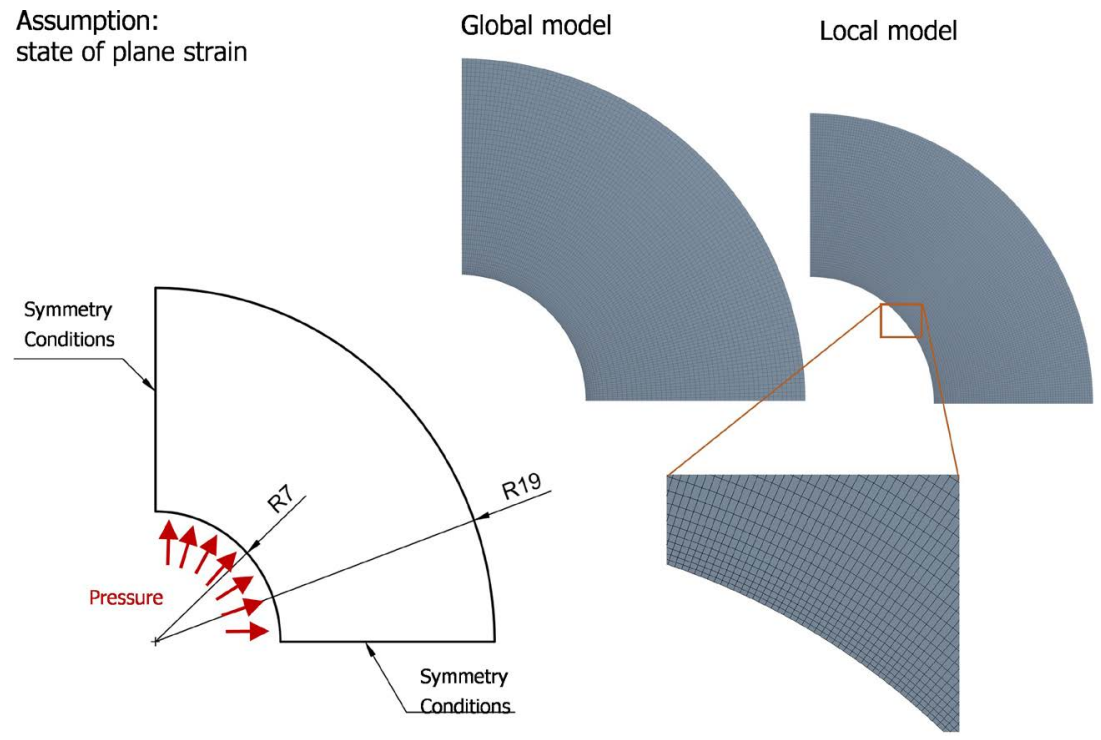

Figure 1. The finite element model of the thick-walled tube.

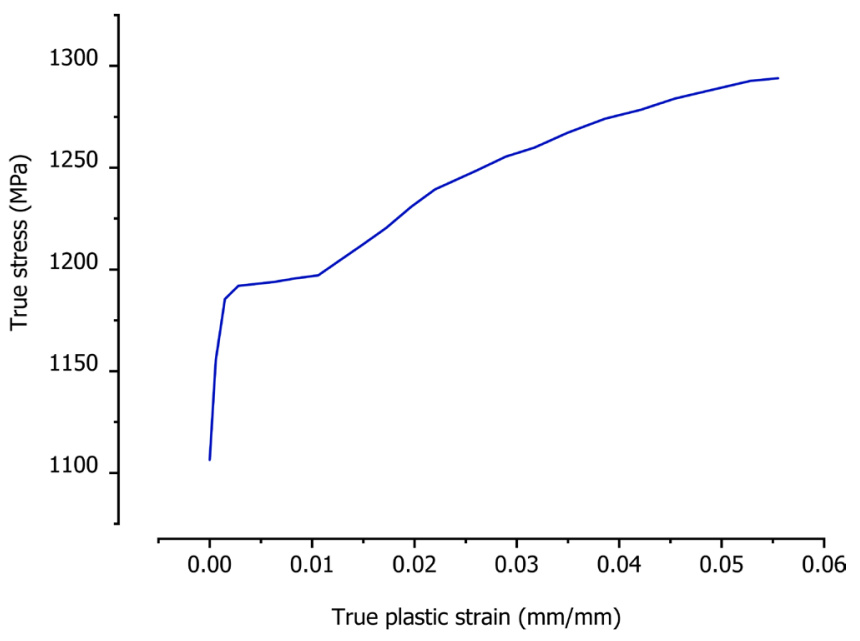

Figure 2. The characteristic of the steel alloy AISI 4340.

Table 1. The summary of the mechanical properties of the material for the thick-walled tube [5] and [16].

\begin{tabular}{lccccccccc}
\hline \multicolumn{10}{c}{ Properties of Steel AISI 4340} \\
\hline$v$ & $\begin{array}{c}E \\
(\mathrm{GPa})\end{array}$ & $\begin{array}{c}\sigma_{y} \\
(\mathrm{MPa})\end{array}$ & $\begin{array}{c}\sigma_{u} \\
(\mathrm{MPa})\end{array}$ & $\begin{array}{c}\sigma_{y}^{\prime} \\
(\mathrm{MPa})\end{array}$ & $\varepsilon_{f}^{\prime}$ & $b$ & $c$ & $K^{\prime}$ & $n^{\prime}$ \\
\hline 0.3 & 200 & 1200 & 1270 & 1898 & 0.67 & -0.09 & -0.64 & 1950 & 0.13 \\
\hline
\end{tabular}

A multiaxial fatigue analysis model was the same as in work [17] and is based on the Wang-Brown method (WB) [18] with a mean stress correction. The authors of that study gave rational argumentation for a selection of the WB me- 
thod. They tested several methods, and the WB with mean correction gives conservative results for the application of the aluminum hydrogen valve. An implementation of that method is done in nCode software, and its model was taken and used in the described analysis. More details of the WB method are presented in the further test in the subsection-Life Estimation Procedure.

The boundary conditions and loading levels are also the same as in the study [5] (Figure 1). The thick-walled tube was loaded by internal pressure assuming plane-strain in the tube. Loading was defined in the four steps in the first one the autofrettage pressure was applied, and in the second one, that pressure was removed to get residual stresses, then two next steps were used to define a working load cycle. The load cycle required the following fatigue analysis. The autofrettage pressure was changing from $650 \mathrm{MPa}$ to $1425 \mathrm{MPa}$ for the intermediate values to obtain fatigue life response in the entire range of possible autofrettage pressure. Two levels of the working pressure of $410 \mathrm{MPa}$ and $510 \mathrm{MPa}$ were analyzed to check if that pressure will influence the optimum autofrettage pressure. The configuration of the analysis load steps is presented in Table 2.

The submodeling depends on an analysis of two models: one is a global mod$\mathrm{el}$, and the other one is a local model. The local model is usually limited only to a small part of the global model; so, it can be meshed with very small elements to improve the accuracy of the strain estimation. The local model is prepared in a way that is cut from the global model. Node displacements of cutting faces from a solution of the global model are used as imposed displacements of the cutting faces of the local model. Since the mesh of the global model and local model are different, an approximation of the displacement between models must be made.

The FE global model of the thick-walled tube was built using first-order 3D elements-Solid 185 type (hex8, ANSYS) to obtain correct strain/stress distribution on the internal surface of the tube. The inflation method in the mesh was used to help distribute elements smoothly from the fine mesh region to the coarse mesh region see Figure 1.

Besides, a submodel (local model) of the internal part with the radius of R16 $\mathrm{mm}$ was created with a fine mesh of $0.15 \mathrm{~mm}$ to confirm that the density of the mesh had neglected influence on the fatigue life results. The same type of elements as for the global model was used for the submodel, and in total, there were 75,075 elements.

The implemented submodeling also has a validation aim since for complex

Table 2. The summary of the loading scheme for the thick-walled tube.

\begin{tabular}{ccc}
\hline & Loading of Tube & \\
\hline Load Steps & Pressure Run & Remarks \\
\hline Step 1 & Autofrettage pressure applied $(650-1425 \mathrm{MPa})$ & One event \\
Step 2 & Release autofrettage pressure $(0.0 \mathrm{MPa})$ & \\
Step 3 & Cycle pressure applied $(410$ or $510 \mathrm{MPa})$ & Pressure cycle \\
Step 4 & Release test cycle pressure $(0.0 \mathrm{MPa})$ & \\
\hline
\end{tabular}


parts, the submodeling is necessary. The investigation showed that the assume mesh of the global model was correct; no significant differences were detected between the global and submodel model results. However, having the results from the submodel ready, it is wise to present them. Therefore, only those results were presented for the thick-walled tube. The submodeling method was used further for the valve design. It is worth mentioning here that there are other techniques used to increase the accuracy of local estimation of stresses, for example, a local increase mesh density. Unfortunately, in the case of very complex mechanical designs, they do not always give as good results as submodeling.

For all analyzed points (different autofrettage pressures), the fatigue life was recorded to create a relationship of the life in function of the autofrettage pressure. That graph was used further for results analysis and comparison with the literature data. The determined relation is after utilized to define the optimum autofrettage pressure (a pressure that maximizes the fatigue lifetime) via the procedure described further in the text.

\subsection{Valve Finite Element Model}

The second analyzed model—the hydrogen valve was much more complicated in terms of geometry and loading; the main idea of the analysis method is the same as for the first model. The examined valve was a newly developed design of the in-tank hydrogen valve for the direct metal laser sintering method (Figure 3). Since the part is a very complex valve, the analysis model must be more sophisticated than in the earlier example.

The primary enhancement is submodeling technics applied extensively to determine the strain field correctly in critical regions of the valve. The submodeling is a well-known method to overcome a problem with a discretization limitation in an FE model due to available computing power; the presented case is an example of that application.
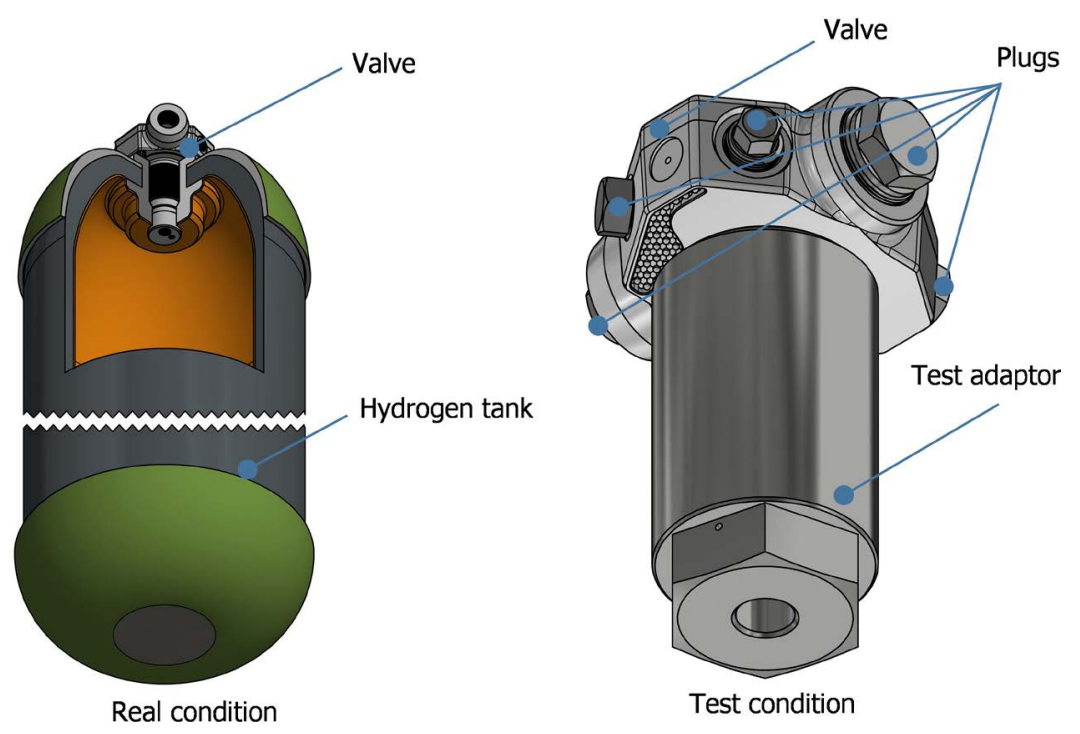

Figure 3. The hydrogen valve, real (left) and test (right) conditions. 
Often, a fine mesh is required to get the right results, for example, in the case of complex geometry. That requires a massive number of elements causing a problem with substantial computation time, especially if the model is non-linear. The right strain distributions in the critical areas are crucial, for instance, for a subsequent fatigue life estimation. Therefore, in the presented work, two submodels were used, as shown in Figure 4. The locations of them were determined by the analysis of the critical regions of the global model results of strain fields.

To make sure high-quality results, the second-order elements Solid 187 (3-D 10-node tetrahedral element, ANSYS) were used with very high mesh density shown in Figure 5. The size of the mesh was globally set for those models on 0.4 $\mathrm{mm}$. Additionally, the internal surfaces of channels were meshed with the size of $0.1 \mathrm{~mm}$, and as results, the number of elements for the submodel 1 and 2 was adequately 701,688 , and 219,786 . The mesh size of the global model was set for $0.93 \mathrm{~mm}$ since the results of the global model are not used to the following fatigue calculation. The total number of elements of the global model was close to 3 million.
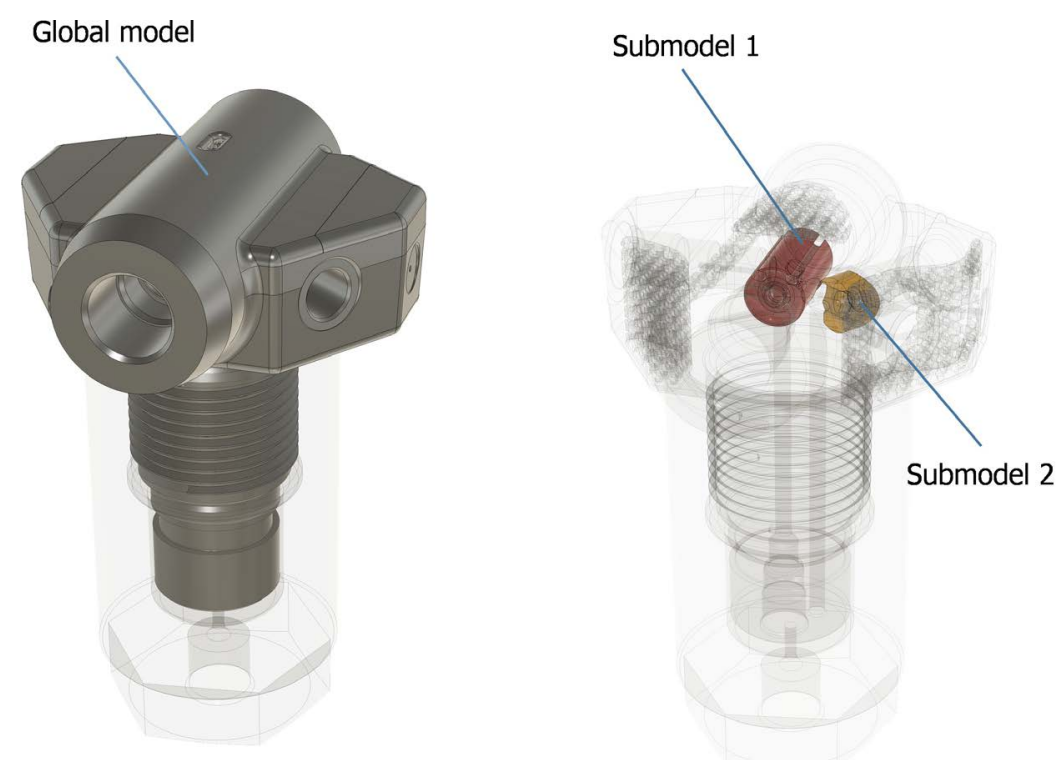

Figure 4. The global and two local models (submodeling) used in the analyses.

Submodel 1

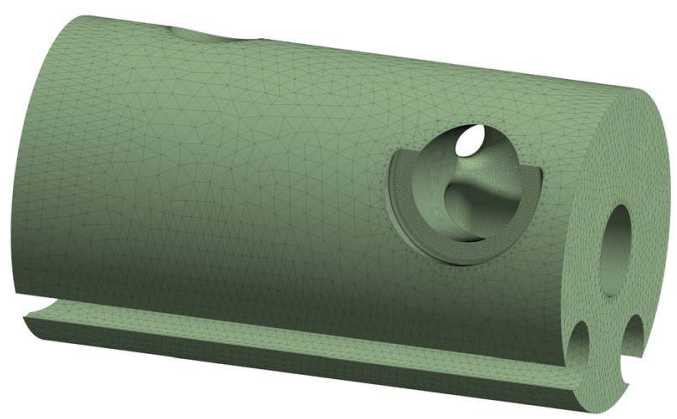

Figure 5. The meshes of the submodels.
Submodel 2

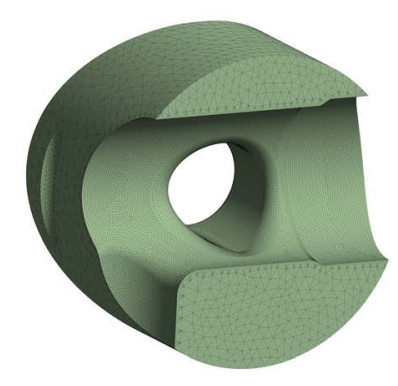


The two critical regions (two submodels) of the valve were pointed out to determine the valve fatigue life. The regions were a part of the valve with channels' intersections. Those locations can be explained on the ground of geometric discontinuities introduced by the channels that cause a local increase in the intensity of a stress field. Therefore, fatigue analyses were focused only on those regions. Several calculation iterations were done to determine a run of the fatigue life of the valve in the function of the applied autofrettage pressure. The relation was afterward used to determine the optimum autofrettage pressure. The developed procedure is described in detail further in the text.

Loading and the boundary conditions are the same as in work [17], and only one modification is implemented; the autofrettage pressure was not constant, but it was changing in a defined range to get the fatigue life response of the design. It should be mentioned here that since the autofrettage pressure changed, also the forces applied on open holes of the valve were changed in direct proportion to that pressure. The values of those forces can be recreated using data in Table 3 by a simple formula; the pressure times the port area.

The presented valve is subjected in regular service to cycling pressure driven by a hydrogen fuel system of a car. As a simplification, pressure cycle test requirements are defined to meet the desired minimum fatigue life of 50,000 with the maximum cycling pressure of $87.5 \mathrm{MPa}$ at the temperature of $85^{\circ} \mathrm{C}$ by Commission Regulation (EU) No 406/2010 2010.

In detail, loading was defined in five steps; in the first step, the thread pre-tension was applied to simulate a stress state in the valve generated by the assembly torque (valve installation). Next, in the second step, the autofrettage pressure was applied, and then in the third step, that pressure was removed to get residual stresses. At that point, two subsequent steps were employed to define the working load cycle. The load cycle was required the following fatigue analyses. The autofrettage pressure was varying from 150 to $300 \mathrm{MPa}$ with intermediate values to find the fatigue life response in the entire range of the autofrettage pressure. Only one level of the working pressure of $87.5 \mathrm{MPa}$ was analyzed in this investigation. The summary of the load steps is placed in Table 4, and the manner of applying the load on the valve is present in Figure 6.

The boundary conditions are shown in Figure 7 reflect test conditions, which are planned to be conducted in the frame of the project. The valve was installed in the adaptor by the threaded connection, and the adaptor is fixed in a test stand in a manner that can slide axially. Additionally, the adaptor is connected

Table 3. The port areas of the valve for the calculations of the axial plug forces.

\begin{tabular}{cc}
\hline Port number & Area of port $\left(\mathrm{mm}^{2}\right)$ \\
\hline 1 & 572.6 \\
2 & 130.7 \\
3 & 254.5 \\
4 & 93.7 \\
\hline
\end{tabular}


Table 4. The summary of the loading scheme for the thick-walled tube.

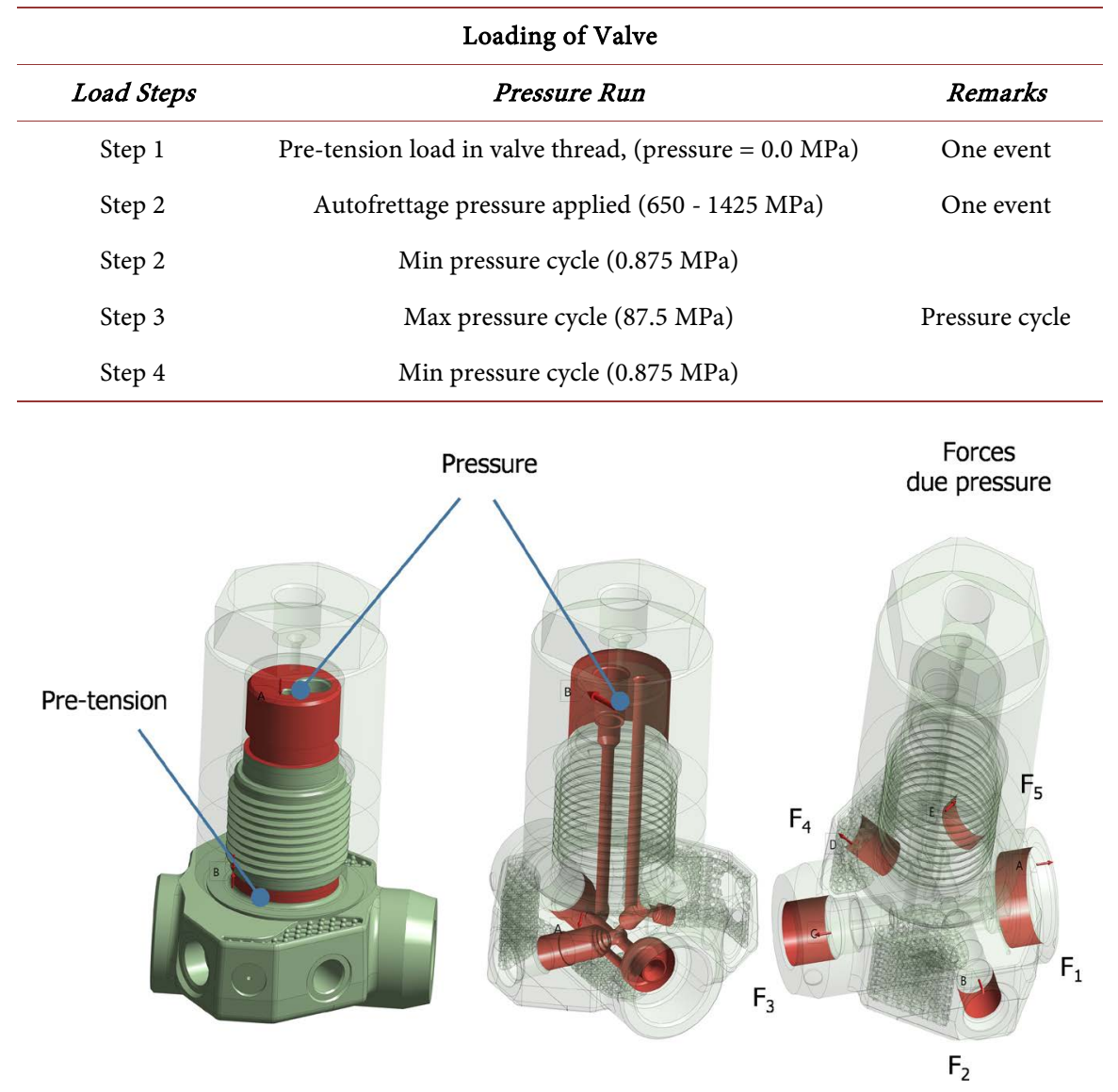

Figure 6. The loading on the hydrogen valve.

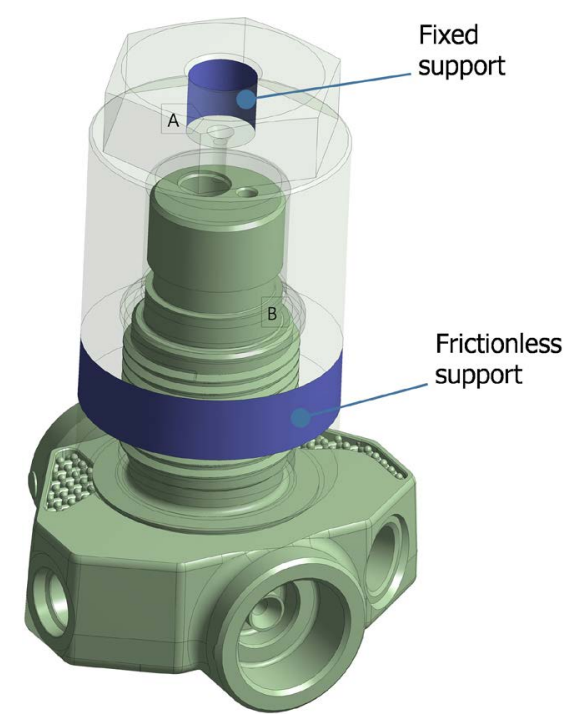

Figure 7. The boundary conditions applied to the hydrogen valve.

with a rigid pipe that supplied pressure. That connection interface (cylindrical face) was fixed to reflect the test conditions.

The contacts between components in the global model are defined as a fric- 
tional contact with the friction coefficient of 0.2 with a formulation of the penalty method, which uses a contact "spring" to establish a relationship between two nodes. The global model has a threaded connection with the steel adaptor needed in the real test conditions to apply pressure and reflecting the physical valve situation in the hydrogen tank. That global FE model may seem over-complicated for the presented project goals. Indeed, the model is complex since it was developed to be used in another purpose, as well.

The material of the valve is aluminum alloy AW $6082 \mathrm{~T} 6$ is the same as in work [17]; a summary of the used material properties are repeated in Table 5 \& Table 6 for clarity of the text. It should be noticed that the proposed material for the valve is wrought aluminum alloy used for forged parts. The shown design of the valve is designed for direct metal laser sintering. The incompatibility comes because the first design of the valve had been done before material test data for sintered material was available. For the presented analyses, the design and material were selected from the earlier work, and that approach is not harmful to the proposed method since the work describes a general method of the autofrettage pressure estimation only.

The adaptor is a new part in comparison earlier author's work and made of the stainless steel alloy-17-4. Both used materials are modeled as bilinear elasto-plastic material with kinematic hardening, and detail data are presented in Table 5.

\subsection{Autofrettage Pressure Approximation for Maximum Fatigue Life}

The optimum autofrettage was estimated by an analysis of a curve minimum fatigue life versus the autofrettage pressure. As a result of previously done steps, that curve is determined for the critical regions. A curve-fitting procedure was used to build the mathematical relation between fatigue life and autofrettage pressure.

The fit function was selected in a form presented in Equation (1); the proposed function gives a good correlation confirmed by Pearson's correlation coefficient of 0.984. Detailed results are shown further in the text in a section devoted to a result

Table 5. The mechanical properties of the materials of the valve [17].

\begin{tabular}{cccccc}
\hline Material & $v$ & $E(\mathrm{MPa})$ & $\sigma_{y}(\mathrm{MPa})$ & $\sigma_{u}(\mathrm{MPa})$ & $E^{\prime}(\mathrm{MPa})$ \\
\hline AW 6082 T6 & 0.33 & 74.6 & 323 & 345 & 819.8 \\
17-4 stainless steel & 0.30 & 187.3 & 580 & $*$ & 2127 \\
\hline
\end{tabular}

Table 6. The mechanical fatigue properties of the valve material (tensile test, $R=-1$ ) [19].

\begin{tabular}{ccccccc}
\hline Material & $\sigma_{y}^{\prime}(\mathrm{MPa})$ & $\varepsilon_{f}^{\prime}$ & $b$ & $c$ & $K^{\prime}(\mathrm{MPa})$ & $n^{\prime}$ \\
\hline AW 6082 T6 & 805.7 & 4.27 & -0.1094 & -1.275 & 425 & 0.0263 \\
\hline
\end{tabular}

Where a new parameter in the table is $E^{\prime}-$ tangential modulus. 
presentation. That coefficient can have any value from the range -1 to 1 with meaning: $0-$ no linear relationship between the variables 1 -data lie on a perfectly straight line with a positive slope, and $-1-$ data lie on a perfectly straight line with a negative slope.

Having the mathematical representation, a maximum of the curve was found, giving the autofrettage pressure that maximizes the valve fatigue life. To find the maximum of the curve, the software Mathcad Prime 5.0 was applied using the procedure "genfit". It is a least-squares nonlinear regression for arbitrary fit functions procedure, which employs an optimized version of the Levenberg-Marquardt method for minimization (Kenneth Levenberg 1944).

$$
f(x)=a_{1} \cdot x^{5}+a_{2} \cdot x^{3}+a_{3} \cdot x^{2}+a_{4} \cdot x
$$

where $a_{1-4}$ are estimation parameters for curve fitting.

\section{Local Elasto-Plastic Strain Limit in Autofrettage Process}

Since there is not any mechanism that guarantees that the estimated maximum fatigue life of the design is in a range acceptable plastic strain level in the autofrettage process, an additional check must be implemented, namely, if allowable plastic strain at critical regions (local) is lower than an elastoplastic strain limit specifically for particular materials. The limit strain is a function of triaxiality in the component and uniaxial strain limits for a material. This strain can be estimated using the equations that proposed ASME code [20] in section Protection Against Local Failure, and the equation is formulated in the following way:

$$
\varepsilon_{L}=\varepsilon_{L u} \cdot \exp \left[-\left(\frac{\alpha_{s l}}{1+m_{2}}\right) \cdot\left(\left\{\frac{\sigma_{1}+\sigma_{2}+\sigma_{3}}{3 \sigma_{e}}\right\}-\frac{1}{3}\right)\right]
$$

where: $m_{2}$-parameter depends on $R, R$-minimum peak stress divided by maximum peak stress, $\alpha_{s l}$-parameter depends on material type, $\sigma_{1-3}$-principal stresses, $\sigma_{e}$-equivalent von Mises stress, $\varepsilon_{L u}$-parameter depends on material properties and on $m_{2}$ and $\varepsilon_{L}$-local elasto-plastic limit of material.

Table 7 is a partial table, only two class materials are taken from ASME, and the table contains equations and constants needed for estimation of the strain limit from Equation (2). For other metal materials, data are available in the described standard.

Table 7. The local strain limit for use in the multiaxial strain limit criterion [20].

\begin{tabular}{cccccc}
\hline Material & $\begin{array}{c}\text { Max } \\
\text { temperature }\left({ }^{\circ} \mathrm{C}\right)\end{array}$ & $m_{2}$ & $\begin{array}{c}\text { Elongation } \\
\text { specified }\end{array}$ & $\begin{array}{c}\text { Reduction of } \\
\text { area specified }\end{array}$ & $\alpha_{s l}$ \\
\hline Ferritic steel & 480 & $0.6 \cdot\left(1-R_{t}\right)$ & $2 \cdot \ln \left(1+\varepsilon_{\text {break }}\right)$ & $\ln \left(\frac{1}{1+A}\right)$ & 2.2 \\
Aluminum & 120 & $0.52 \cdot\left(0.98-R_{t}\right)$ & $1.3 \cdot \ln \left(1+\varepsilon_{\text {break }}\right)$ & $\ln \left(\frac{1}{1+A}\right)$ & 2.2 \\
\hline
\end{tabular}

a. Maximum of columns above if elongation and reduction of area specified else $m_{2}$; Where: $m_{2}-$ material parameter $R_{t}=\sigma_{y} / \sigma_{u}, A$-reduction of area, and $\varepsilon_{\text {break }}$-elongation at break. 


\section{Life Estimation Procedure}

The fatigue life estimation was done using the method described in work [17]; the estimation was done for several values of the autofrettage pressure to determine a math dependence of the fatigue life on the autofrettage pressure in the predefined range. The entire life assessment method based on the fatigue life analysis handled through nCode software [15], which estimates the minimum number of the working cycles, at which cracks would nucleate on surfaces of the critical regions. Only one configuration of the working pressure cycle was analyzed according to the test requirements for the valve analysis and two levels of the pressure for the thick-walled tube.

The authors used the crack initiation method for life estimation only. They did not analyze the total life of a part since it required using elasto-plastic fracture mechanics. Simulation of crack propagation through high residual compression stress field and then the tensile field is needed, where the elasto-plastic state is present.

Moreover, the primary goal of the project was to develop the method for complex parts (geometry) to determine the optimum autofrettage pressure, and that requires simplifications. The authors believe that the limitation to the criteria to crack initiation only helps to simplify the procedure without generating a significant error in the estimation. In other words, the authors assume that the optimum autofrettage pressure predicted based on the crack initiation life is close to one that could be determined based on the total life approach.

The life assessment method includes the strain-life (EN) approach since plastic-strain is expected to induce crack initiations on those surfaces. The plastic strain was included in the analysis form FE analyses directly; therefore, a further correction was not needed in the fatigue calculations. A stress-strain history was analyzed by combining the two last static load-cases representing the first loading cycle. The material was then assigned to the analyzed component with the properties shown in Tables 1-6 are adopted.

To obtain correct strain/stress distribution, the described submodeling technique was used for both models.

$$
\frac{\gamma_{\max }+S \cdot \delta \varepsilon_{n}}{1+v^{\prime}+S \cdot\left(1-v^{\prime}\right)}=\frac{\sigma_{f}^{\prime}-2 \sigma_{n, \text { mean }}}{E} \cdot\left(2 N_{f}\right)^{b}+\varepsilon_{f}^{\prime} \cdot\left(2 N_{f}\right)^{c}
$$

where:

$\gamma_{\max }-$ maximum shear strain amplitude in critical plane.

$S$-parameter $S$ is representing the material's sensitivities in crack growth to the normal strain across the maximum shear plane. It can be determined by correlating push-pull and torsion fatigue data. For all presented analyses, it was always, $S=1$.

$N_{f}$-half number of reversals to failure.

$\sigma_{n, \text { mean }}-$ mean stress, normal to maximal shear strain plane.

$\delta \varepsilon_{n}$-normal strain range on maximal shear strain plane.

$v^{\prime}$-effective Poisson ratio. 
The multi-axial fatigue engine was used to calculate the fatigue life employing the Wang-Brown theory [21] with mean stress correction with a certainty of survival of 50\%. The Wang-Brown with mean stress correction uses the Morrow approach, as shown in Equation (3). The whole process of the estimation of the relation of fatigue life versus the autofrettage pressure is presented in the diagram (Figure 8).

The loop presented in the diagram was made to estimate the fatigue life for the different autofrettage pressure; the number of repeats was set for 6 . The analyzed points of the autofrettage pressure were 150, 175, 200, 225, 250, $300 \mathrm{MPa}$, and these 6 points were sufficient to create the relation the following curve fitting.

Additionally, $K_{\text {TREAT }}$-a surface treatment parameter was used in nCode to include surface roughness of $\mathrm{Ra}=6.3 \mu \mathrm{m}$ of the analyzed parts to take account of a real surface condition in the life estimation.

\section{Optimum Autofrettage Pressure Analysis Method}

The procedure of the estimation of the optimum autofrettage pressure that gives the longest fatigue life is presented in Figure 9. The steps started from the estimation of the curves-the fatigue life versus the autofrettage pressure created for the critical regions of the structure.

The new parameters in Figure 9 are $p$-pressure in valve, $p_{o}$-autofrettage pressure, $p_{\text {opt }}$-optimum autofrettage pressure, $p_{x}$-autofrettage for maximum

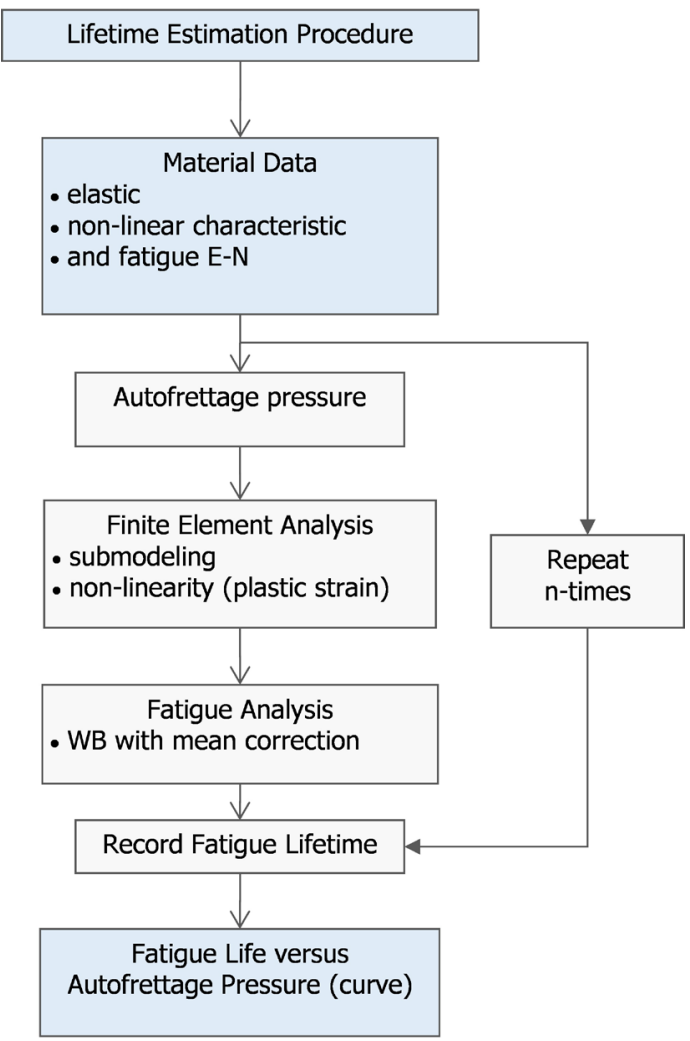

Figure 8. The diagram of the estimation of fatigue life in the function of the autofrettage pressure. 


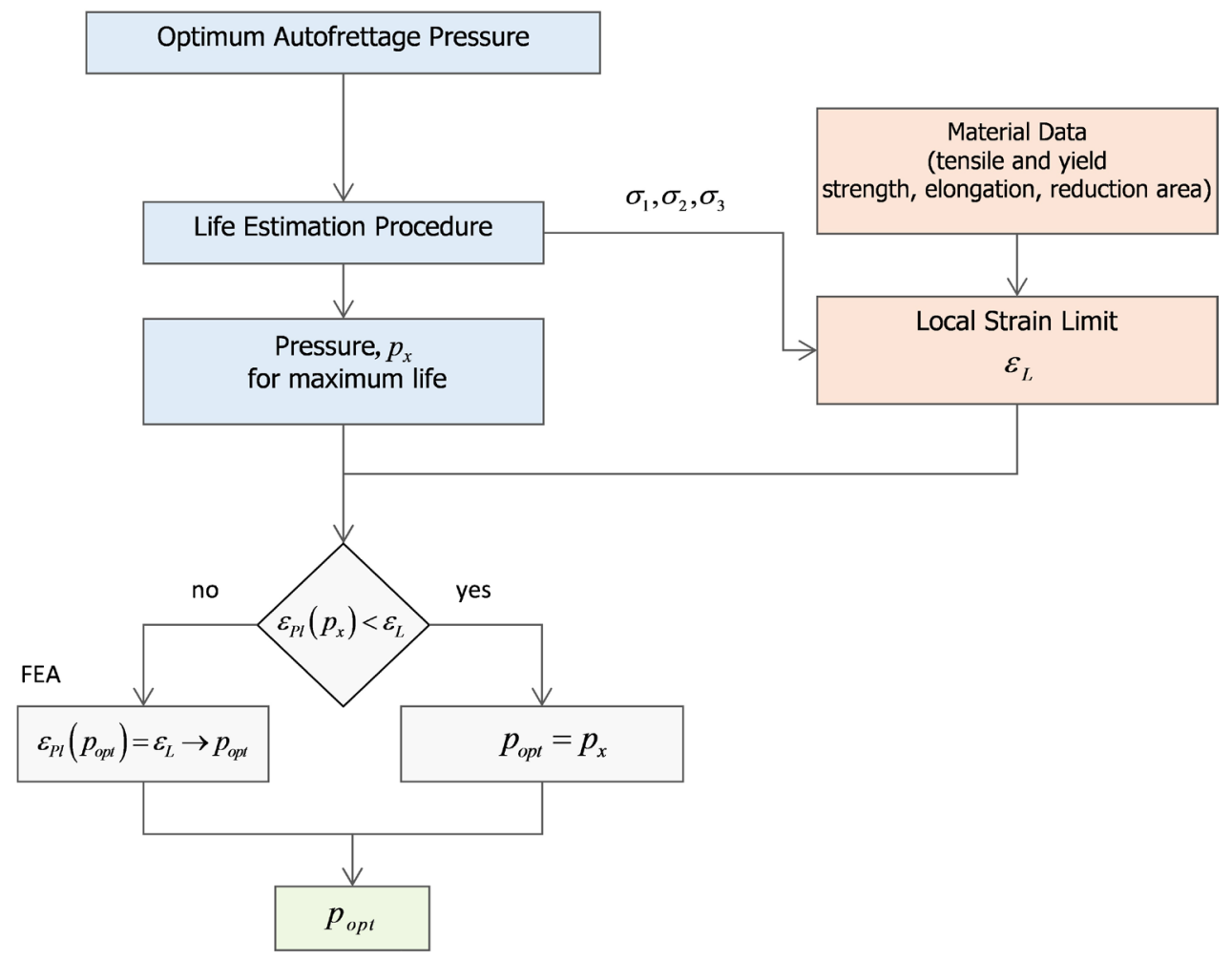

Figure 9. The diagram of the procedure of the estimation of the optimum autofrettage pressure.

fatigue life, and $\varepsilon_{p l}$-local plastic strain in structure.

Giving those math dependencies, the autofrettage pressure was determined based on the method described in the section-Autofrettage Pressure Approximation for Maximum Fatigue Life. Then, the local strain limit was estimated for the determined autofrettage pressure. That was done based on the FE results and the method described in the subsection-Local Elasto-Plastic Strain Limit in Autofrettage Process. Subsequently, an investigation was performed if the plastic strain in the critical regions of the structure is lower than the strain limit. If the answer is yes, the determined autofrettage pressure has the optimum value maximizing the fatigue life. Otherwise, based on the FEA results, the optimum autofrettage pressure should be determined as the pressure which causes the plastic strain having the closest value of the local strain limit, but no higher than that limit.

The proposed estimation method does not take into account other criteria like maximum allowable pressure because of safety, existing equipment, or cost restrictions. That constraint should be added to the top of the made investigation.

\section{Results and Discussion}

\subsection{Results of Thick-Walled Tube}

The first set of tasks aimed to determine the optimum autofrettage pressure for the thick-tube and compare the results with findings from the literature. The developed method was applied to achieve the goals. The first set of analyses ex- 
amined the impact of the autofrettage pressure on the fatigue life of the tube subjected to the cycling load. To make life assessment, it is crucial to discover, where the critical region of the structure determining the fatigue life is. As Figure 10 presents for the autofrettage pressure of $800 \mathrm{MPa}$, the critical region for the fatigue life is the internal bore surface. Further analysis shows that the location of the critical region is not changing with any modifications of the autofrettage pressure.

The response of the structure for the increase of the autofrettage pressure for two stages of the pressure cycle is shown in Figure 11. Looking at the figure, it is apparent that both curves have a maximum value (fatigue life) at the same autofrettage pressure of around $1400 \mathrm{MPa}$. Then, both curves instantly drop just after their maximum presenting, then the very short fatigue life.

Looking at Figure 12, it is apparent that the plastic strain level does not limit the autofrettage pressure for the investigated structure; the local limit strain is much higher than the detected plastic strain in the whole range of the analyzed
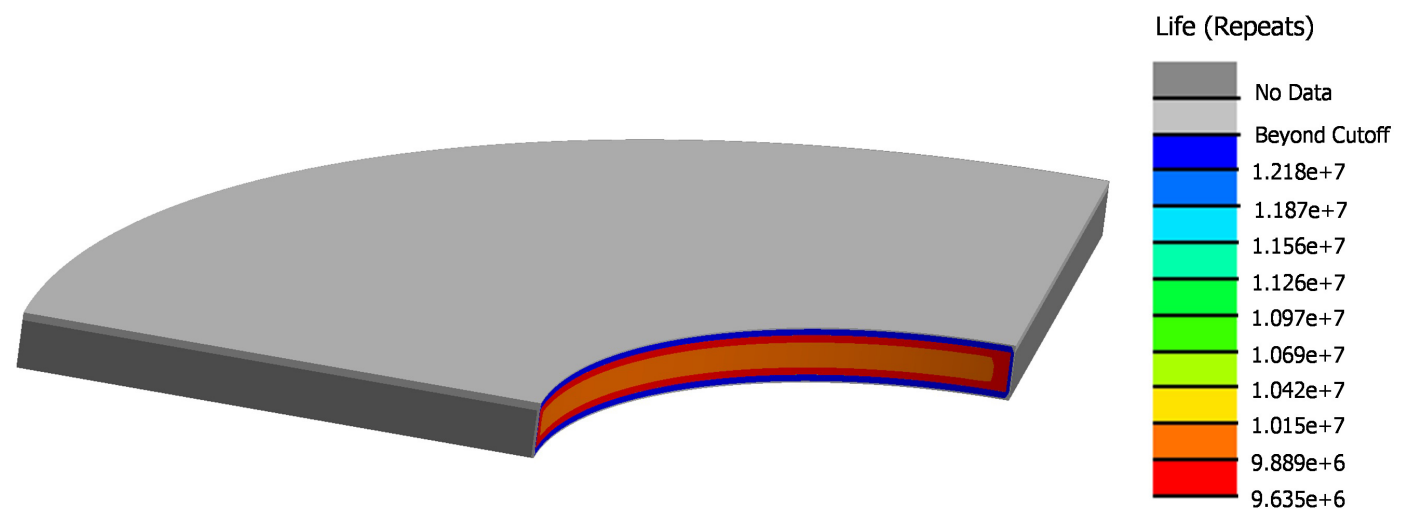

Figure 10. The fatigue life for the thick-tube at the critical region for the autofrettage pressure of $800 \mathrm{MPa}$ and the working pressure of $410 \mathrm{MPa}$.

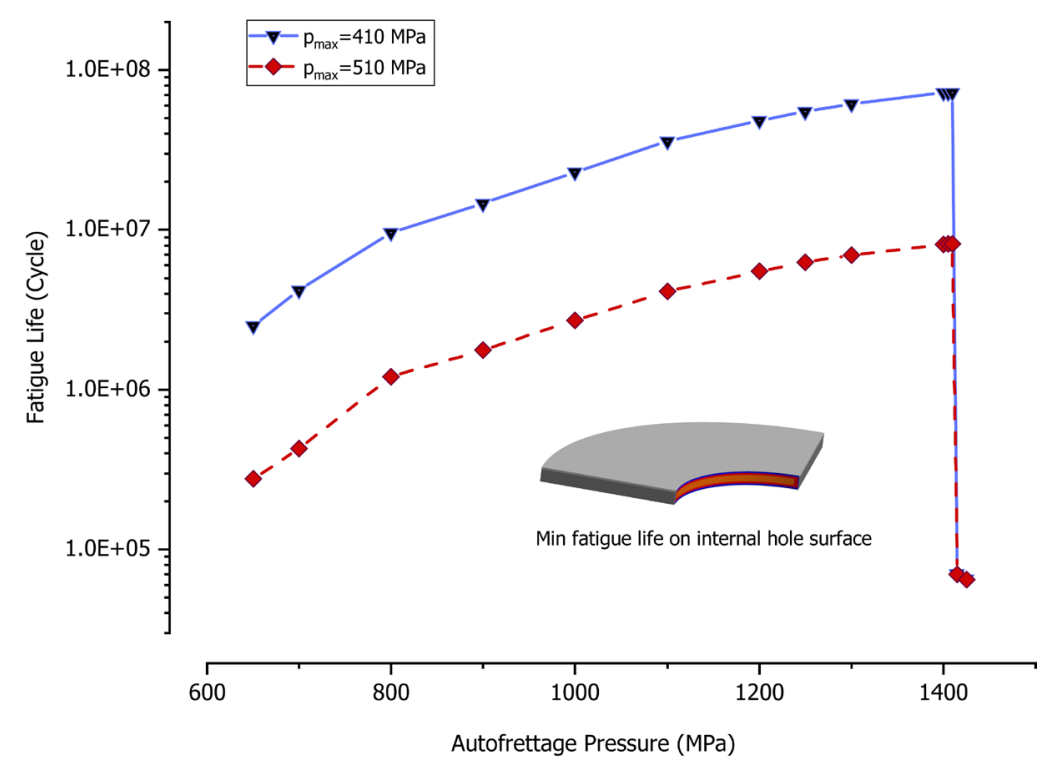

Figure 11. The fatigue life for the thick-tube versus the autofrettage pressure. 


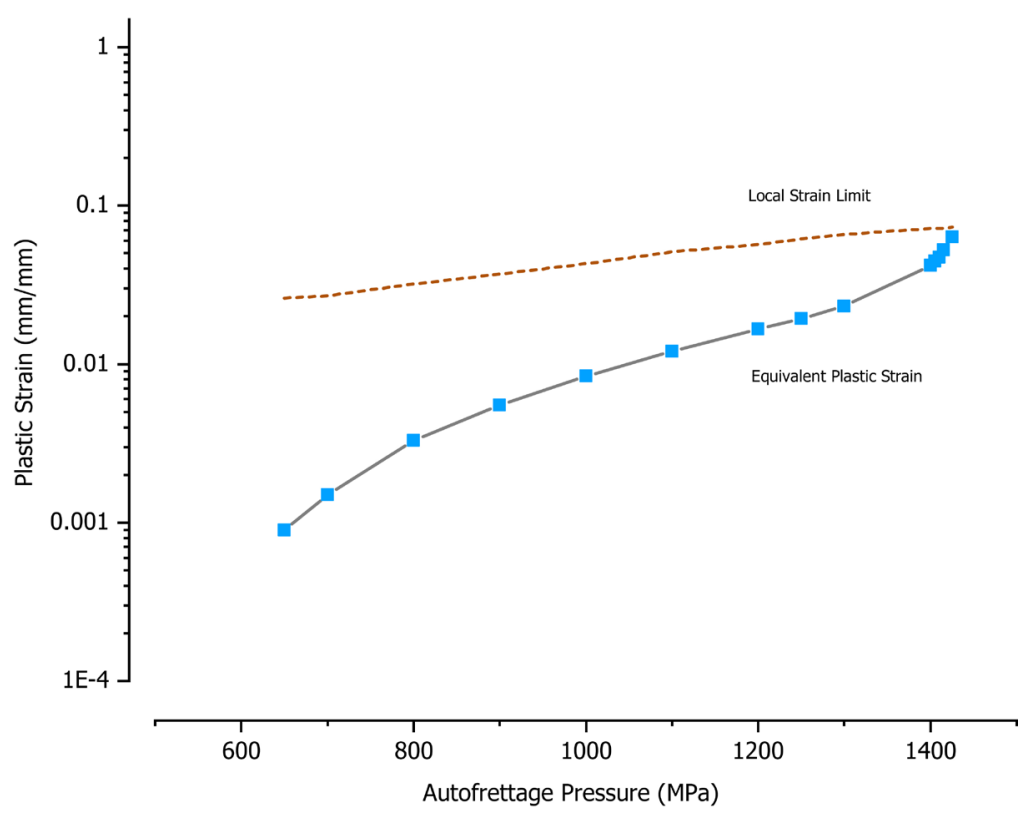

Figure 12. The maximum equivalent plastic strain the thick-tube versus the autofrettage pressure.

pressure. Only at the high autofrettage pressure, the maximum plastic strain approaches the strain limit.

In reviewing the literature, no data was found on the association between the autofrettage pressure and the fatigue lifetime for the thick-tubes and estimation of the optimum autofrettage pressure maximizing the fatigue life. There is reported work [5], where the optimum autofrettage pressure of $936.3 \mathrm{MPa}$ for the presented tube is determined based on minimizing the maximum von Mises stress at the critical section (elasto-plastic radius). In contrary to the presented work, a similar effect was not detected at the elasto-plastic radius that determined the optimum autofrettage pressure. This observation may support the hypothesis that the results achieved by [5] are a consequence of made assumptions for the material model and failure criteria.

The presented outcomes show that the internal bore surface determines the fatigue life and the increase of the autofrettage pressure to improve the fatigue life until the section of the tube is fully plasticized. The instant drop of the fatigue life is caused by the effect of the completely plasticized section of the tube. In other words, the autofrettage pressure creates high compression stress on the internal bore surface improving the fatigue life until there is a significant surrounding elastic zone of the material is present; when the elastic zone does not exist because of plastic deformation of the whole section, the positive effect suddenly disappears.

One interesting finding is that the autofrettage pressure produces the maximum equivalent plastic strain on the internal diameter, which is lower than the local strain limit for the entire range of the analyses autofrettage pressure. These results suggest that the local strain does not limit the autofrettage pressure. Thus, 
the optimum pressure can be found in analyzing Figure 11 and taking into consideration practical constraints like safety aspects, available high-pressure equipment, and acceptable permanent deformation of the thick-walled tube. On the ground of those parameters, the maximum autofrettage pressure can be determined. The listed constraints are expected to cause the pressure to be lower than the pressure of the maximum life (Figure 11).

\subsection{Results of Hydrogen Valve}

The next section of the result presentation concerns the hydrogen valve the optimum pressure estimation. The described method was used to get the presented results, and only selected results are presented, having the most significant influence of the detection of the optimum autofrettage pressure. Figure 13 provides the results as an example of the described analyses. The fatigue life distributions were plotted for two submodels at the autofrettage pressure of $200 \mathrm{MPa}$, and all the results are obtained for the defined test pressure cycle. As can be seen from the figure, the critical regions (minimum life) of the valve are on the intersection of the internal channels. The life of the valve is limited by the region shown in the submodel 1, there the fatigue life is the shortest. The locations of the critical region of the valve are independent of the applied autofrettage pressure.

Further analysis of the data reveals the run of the fatigue life of both submodels in the function of the autofrettage pressure (Figure 14). Both curves have a maximum, but for the proposed method, the curve of the submodel 1 gives the shortest fatigue life; therefore, it is considered further. To conclude, the life of the submodel 1 determines the entire valve life. Therefore, only this curve is studied further for the optimum autofrettage pressure estimation.

That curve has a maximum of 1.6E5 load cycles at the autofrettage pressure of $207 \mathrm{MPa}$; the value was determined using the described curve fitting method and the optimization. The calculated pressure values are the optimum one since

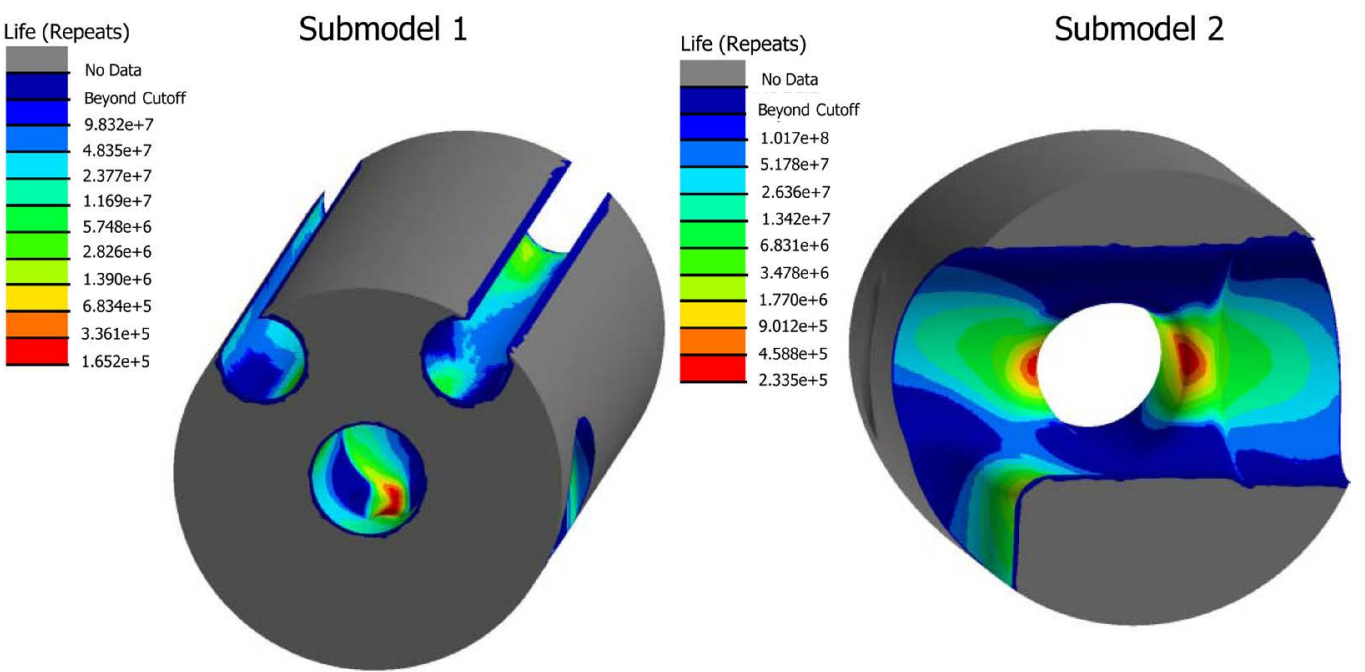

Figure 13. The fatigue life for the hydrogen valve, submodel 1, and submodel 2 at the autofrettage pressure of $200 \mathrm{MPa}$ and the working pressure of $87.5 \mathrm{MPa}$. 
maximizing the fatigue life of the entire valve.

The existence of the maximum of the curves in Figure 14 is determined by mean stress, normal to the maximal shear strain plane at the critical region/node. The direction of the critical plane varies for the different autofrettage pressure due to imposed changing plastic strain. The minimum value of that normal stress (maximum compression stress) determines the characteristic of the curves in Figure 14. That effect is caused directly by the used Wang-Braun method with mean stress correction for the fatigue life determination; Equation (3) shows this. That normal stress $\sigma_{n \text {,mean }}$ adds the mean stress effect in the Wang-Brown method in the way the compression mean stress extends the fatigue life, which is consistent with the observation. For case-B for the planes of the maximum shear defined by [18] in the analyzed valve (submodel 1), the maximum normal stresses to the shear planes have the minimum value for the peak life presented in Figure 14.

The equivalent plastic strain at the critical region of the submodel 1 is estimated and compared with the local limit strain in Figure 15. The results of the comparison show a clear tendency that the local strain limit is higher than the equivalent plastic strain until the autofrettage pressure of $225 \mathrm{MPa}$. Then, the limit strain is smaller than the maximum plastic strain, which concludes that this pressure region should not be used in a real application since there is a risk of failure of the valve. Interestingly, there is a difference between the thick-tube results and the valve ones; it means that the plastic strain criterion determines the autofrettage pressure in the critical region for the valve.

It may be noticed that the plastic limit strain is calculated based on the procedure presented and concluded by Equation (2). In this case, it does not take

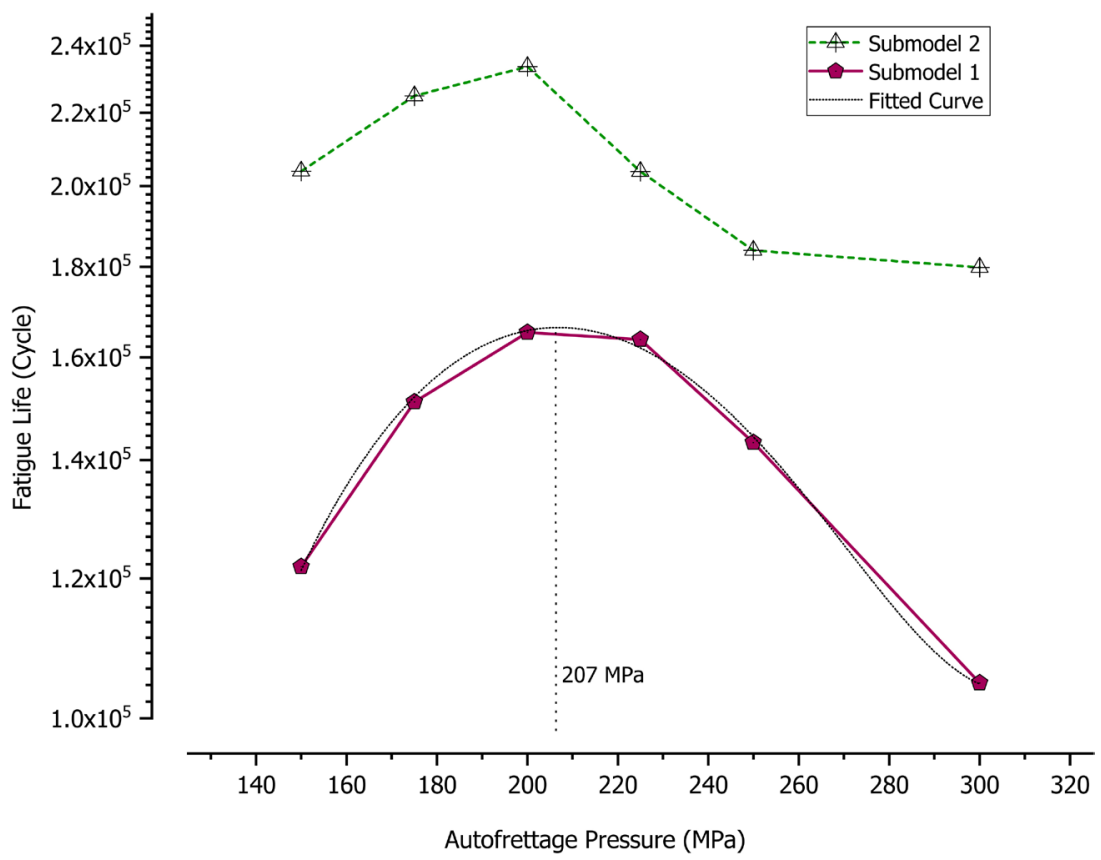

Figure 14. The fatigue life of the hydrogen valve versus the autofrettage pressure. 


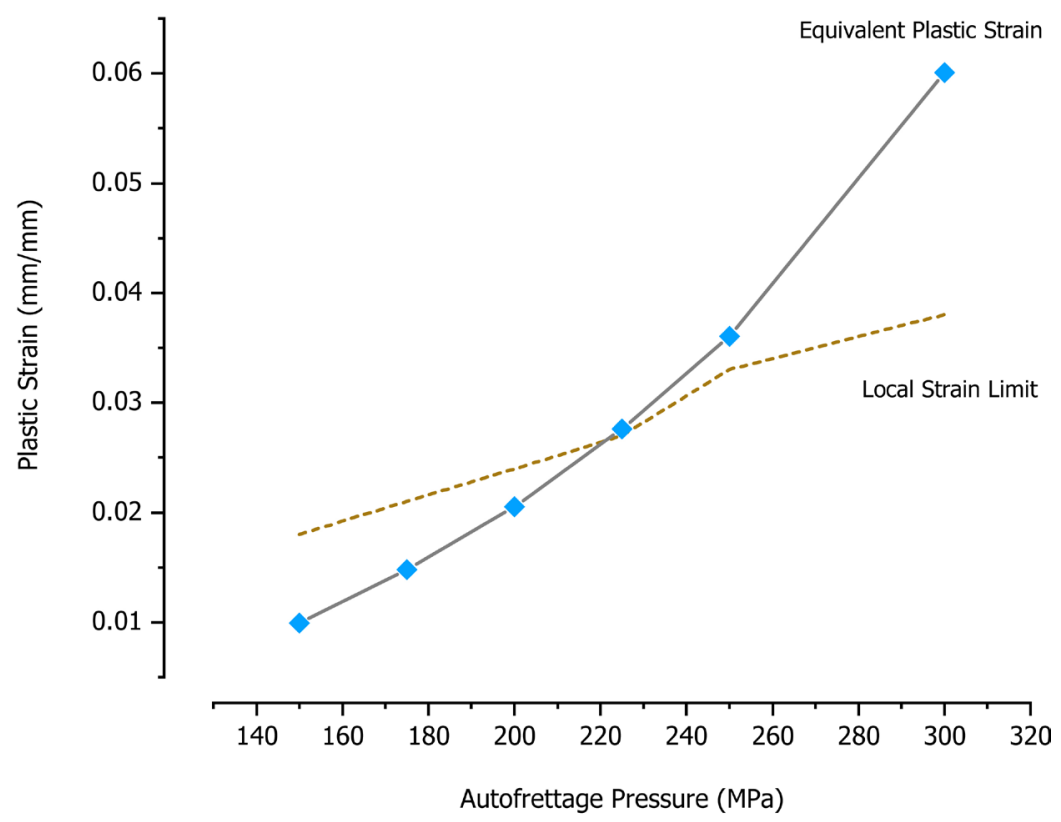

Figure 15. The maximum equivalent plastic strain (submodel 1) versus the autofrettage pressure.

into account elongation at break and reduction of the area since they are unknown. Therefore, the strain limit is calculated in a conservative way getting a small value from Equation (2). Having tensile test data, the stress limit will have a higher value closer to the real local strain limit of the material.

One interesting finding is that the autofrettage pressure of the complex valve can be determined based on the fatigue strength criteria, and the clear maximum of the fatigue life can be seen for the particular autofrettage pressure range. An explanation for this might be that the compression stresses created by the autofrettage pressure at the critical region have an optimum distribution and values maximizing the fatigue lifetime. A remarkable finding is that the maximum of life can be easily detected by the presented method. In contrast to earlier findings for the thick-tubes, here, the maximum life is detected for rather small autofrettage pressure and with the visible maximum. The reduction of life after reaching the maximum is not as considerable as it can be seen for the thick-tube. This result may be explained because, in the case of the valve, the drop of the life is not caused by the wholly plasticized section, but the change of the compression stress state for less favorable for the fatigue resistance. These findings suggest that each of the analyzed cases using the following method can be very different since the geometry of critical regions can vary considerably, and thus no general tendency can be determined.

The presented results are significant in at least two major aspects. Firstly, the elaborated method gives an intuitive tool for investigation of the optimum autofrettage pressure for geometrically complex parts loaded by cycling loads. Secondly, it can reduce time and cost, principally for new product development, when detailed knowledge of the structure is still not built up. 
It may be noticed that material nonlinear characteristic is an important parameter that drives the autofrettage pressure; therefore, tensile tests of specimens are required as at least pre-requisite for the proposed method, so to be sure that complete analysis gives reliable results. Fatigue material data (E-N characteristic, monotonic, and cycling properties) ideally should be known as well, but they are not so critical, and for the first assessment, an estimation can be done based on the tensile test results using the method proposed by authors in the work [12]. The estimated fatigue data can be accepted since the focus of the analysis is more on a location of the maximum of the curve-the fatigue life versus the autofrettage pressure than the value fatigue life itself.

Despite these promising results, questions remain to whether the theoretical investigation can benefit in real test conditions with the improvement of the fatigue life of new designs and how sensitive a real structure will be, including all manufacturing defects on a change of the autofrettage pressure. Therefore, for sure, further investigation is needed to confirm the correctness of the proposed method on the ground of tests.

\section{Conclusions}

The study has shown the new method of the estimation of the optimum autofrettage pressure for geometrically complex parts. The procedure is less sensitive for a biassed assessment, as presented by the author [10]. The method can be automated, as shown in the presented example of ANSYS Workbench and nCode.

The evidence from this study suggests that the autofrettage pressure can be determined in a way it maximizes fatigue life, and the developed method can be used for different design structures as presented in two examples.

In general, it seems that the proposed method can be implemented in an engineering office bearing in mind minimum requirements robust FEA software with the nonlinear capability and fatigue analysis software.

With regard to the developed method, some limitations need to be acknowledged; further validation of the method is required to prove the theoretical study by test validation and answer for a question whether the fatigue life improvement will be detectable during real tests. The source of uncertainty is the manufacturing and material defects of real parts that may mask achieved improvement.

To clarify doubts, tests are planned in the short future, and the results will be published. Despite its limitations, the research adds to our knowledge of the new element showing how to benefit from the autofrettage process.

\section{Disclosure Statement}

The authors do not report potential conflicts of interest with respect to the research, authorship.

\section{Funding}

The authors disclosed receipt of the following financial support for the research, 
authorship, and/or publication of this article: We funded this work through University Luxembourg in the frame of one Ph.D. structural position.

\section{Conflicts of Interest}

The authors declare no conflicts of interest regarding the publication of this paper.

\section{References}

[1] Jacob, L. (1907) La Résistance et l'équilibre élastique des tubes frettés, Meml. L'artillerie Nav. (In French)

[2] Lamé, G. (1852) Leçons sur la théorie mathématique: De l'élasticité des corps solides. Paris. (In French)

[3] Gibson, M.C., Hameed, A. and Hetherington, J.G. (2014) Investigation of Residual Stress Development during Swage Autofrettage, Using Finite Element Analysis. Journal of Pressure Vessel Technology, 136, Article ID: 021206. https://doi.org/10.1115/1.4025968

[4] Wagner, L. (2002) Shot Peening. Wiley-VCH Verlag GmbH \& Co. KGaA, Weinheim.

[5] Çandar, H. and Filiz, H. (2017) Optimum Autofrettage Pressure for a High Pressure Cylinder of a Waterjet Intensifier Pump. Universal Journal of Engineering Science, 5, 44-55.

[6] Zhu, R. and Yang, J. (1998) Autofrettage of Thick Cylinders. International Journal of Pressure Vessels and Piping, 75, 443-446.

https://doi.org/10.1016/S0308-0161(98)00030-1

[7] Wahi, N., Ayob, A. and Elbasheer, M.K. (2011) Effect of Optimum Autofrettage on Pressure Limits of Thick-Walled Cylinder. International Journal of Environmental Science and Development, 2, 329-333. https://doi.org/10.7763/IJESD.2011.V2.146

[8] Bauschinger, J. (1886) Über die Veränderung der Elastizitätsgrenze und die Festigkeit des Eisens und Stahls durch Strecken und Quetschen, durch Erwärmen und Abkühlen und durch oftmals wiederholte Bean-spruchungen. On the Change of the Elastic Limit and Strength of Iron and st, 1886, Mittheilungen, 13, 1-62. (In German)

[9] Thumser, R., Bergmann, J.W. and Vormwald, M. (2002) Residual Stress Fields and Fatigue Analysis of Autofrettaged Parts. International Journal of Pressure Vessels and Piping, 79, 113-117. https://doi.org/10.1016/S0308-0161(01)00137-5

[10] Sellen, S., Maas, S., Andreas, T., Plapper, P., Zürbes, A. and Becker, D. (2016) Design Rules for Autofrettage of an Aluminum Valve Body. Fatigue \& Fracture of Engineering Materials \& Structures, 39, 68-78. https://doi.org/10.1111/ffe.12328

[11] Okorokov, V., MacKenzie, D., Gorash, Y., Morgantini, M., van Rijswick, R. and Comlekci, T. (2018) High Cycle Fatigue Analysis in the Presence of Autofrettage Compressive Residual Stress. Fatigue \& Fracture of Engineering Materials \& Structures, 41, 2305-2320. https://doi.org/10.1111/ffe.12866

[12] Lopez, Z. and Fatemi, A. (2012) A Method of Predicting Cyclic Stress-Strain Curve from Tensile Properties for Steels. Materials Science and Engineering: A, 556, 540-550. https://doi.org/10.1016/j.msea.2012.07.024

[13] Mac, T., Fonseca Junior, I. and Magnabosco, R. (2012) Evaluation of Methods for Estimating Fatigue Properties Applied to Stainless Steels and Aluminum Alloys. 
Tecnologia em Metalurgia, Materiais e Mineração, São Paulo, 9, 284-293. https://doi.org/10.4322/tmm.2012.040

[14] ANSYS (2018) Academic Research Mechanical, Release 19.

[15] HBM Prenscia (2018) nCode DesignLife-CAE fatigue analysis software-nCode Release 2018.

[16] Boardman, B. (1990) Fatigue Resistance of Steels. In: ASM Handbook, Volume 1: Properties and Selection: Irons, Steels, and High-Performance Alloys, 10th Edition, ASM International, 673-688. https://doi.org/10.31399/asm.hb.v01.a0001038

[17] Cao, T.B. and Kedziora, S. (2019) Innovative Designs of an In-Tank Hydrogen Valve towards Direct Metal Laser Sintering Compatibility and Fatigue Life Enhancement. Structural and Multidisciplinary Optimization, 56, 2319-2340. https://doi.org/10.1007/s00158-018-2174-1

[18] Brown, M.W. and Miller, K.J. (1973) A Theory for Fatigue Failure under Multiaxial Stress-Strain Conditions. Proceedings of the Institution of Mechanical Engineers, 187, 745-755. https://doi.org/10.1243/PIME_PROC_1973_187_161_02

[19] Sellen, S. (2014) Untersuchung der Ermüdungsfestigkeit von Komplexen Innendruckbelasteten Aluminiumgeometrien und der Lebensdauersteigerung durch Autofrettage. PhD Thesis, University of Luxembourg, Luxembourg. (In German) http://hdl.handle.net/10993/20678

[20] ASME (2012) Companion Guide to the ASME Boiler \& Pressure Vessel Code. Volume 2, ASME, 4th Edition, ASME Press, New York.

[21] Wang, C.H. and Brown, M.W. (1996) Life Prediction Techniques for Variable Amplitude Multiaxial Fatigue Part 1: Theories. Journal of Engineering Materials and Technology, 118, 367. https://doi.org/10.1115/1.2806821 